\title{
Edible Bird's nest extract as a chondro-protective agent for human chondrocytes isolated from osteoarthritic knee: in vitro study
}

Kien-Hui Chua ${ }^{1}$, Ting-Hun Lee ${ }^{2^{*}}$, Kamini Nagandran ${ }^{2}$, Nor Hamdan Md Yahaya ${ }^{3}$, Chew-Tin Lee ${ }^{4}$, Eddie Tan Ti Tjih ${ }^{5}$ and Ramlan Abdul Aziz ${ }^{2}$

\begin{abstract}
Background: Osteoarthritis $(\mathrm{OA})$ is a degenerative joint disease that results in the destruction of cartilage. Edible Bird's Nest (EBN) extract contains important components, which can reduce the progression of osteoarthritis and helps in the regeneration of the cartilage. The present study aimed to investigate the effect of EBN extract on the catabolic and anabolic activities of the human articular chondrocytes (HACs) isolated from the knee joint of patients with $O A$.

Methods: A single batch of EBN extract was prepared with hot-water extraction and coded as HMG. HACs were isolated from the knee joint cartilage removed during surgery. The optimum concentration of HMG for HAC cultures was determined using MTT assay. The effect of HMG on the catabolic and anabolic genes' expression in HACs was measured by real-time PCR. The total amount of prostaglandin $\mathrm{E}_{2}\left(\mathrm{PGE}_{2}\right)$ production was determined by ELISA method, and the total sulphated glycosaminoglycan (GAGs) production was quantified by 1,9-dimethylmethylene blue (DMMB) assay.

Results: MTT assay showed 0.50\% - 1.00\% HMG supplementation promoted HACs proliferation. HMG supplementation was able to reduce the catabolic genes' expression in cultured HACs such as matrix metalloproteinases (MMP1 \& MMP3), Interleukin 1, 6 and 8 (IL-1, IL-6 \& IL-8), cyclooxygenase-2 (COX-2) and inducible nitric oxide synthase (iNOS). Prostaglandin $\mathrm{E}_{2}\left(\mathrm{PGE}_{2}\right)$ production was significantly reduced in $\mathrm{HAC}$ cultures supplemented with HMG. With regard to anabolic activity assessment, type II collagen, Aggrecan and SOX-9 gene expression as well as SGAG production was increased in the HMG supplemented groups.
\end{abstract}

Conclusion: Edible Bird's Nest extract coded as HMG demonstrated chondro-protection ability on human articular chondrocytes in vitro. It reduced catabolic activities and increased cartilage extracellular matrix synthesis. It is concluded that HMG is a potential agent in the treatment of osteoarthritis.

\section{Background}

Osteoarthritis $(\mathrm{OA})$ results in progressive degeneration of the articular cartilage. OA is caused by the increase in the production of matrix metalloproteinases (MMPs), proinflammatory cytokines and catabolic mediators which destroy the cartilage matrix [1]. Usually, there is a balance in the anabolic and catabolic activities in the articular chondrocytes which are involved in the remodelling of the extracellular matrix (ECM). Disturbance in the normal

\footnotetext{
* Correspondence: lee@ibd.utm.my

${ }^{2}$ Institute of Bioproduct Development, Universiti Teknologi Malaysia, Skudai, Johor 81310, Malaysia

Full list of author information is available at the end of the article
}

balance triggers the pathological changes in OA and this causes an increase in inflammatory factors and cytokine gene expressions [2]. Pro-inflammatory cytokines such as Interleukin- $1 \beta, 6$ and 8 (IL-1 $\beta$, IL- 6 and IL- 8 ) initiate the development of OA by increasing the number of inflammatory cells in the synovial tissue thereby increasing the amount of MMPs and inhibiting the production of proteoglycans $[3,4]$. Subsequently, the release of the catabolic mediators such as Prostaglandins $\mathrm{E}_{2}\left(\mathrm{PGE}_{2}\right)$, cyclooxygenase-2 (COX-2) and inducible nitric oxide synthase (iNOS), contribute to the catabolic consequences of $\mathrm{OA}[5]$.

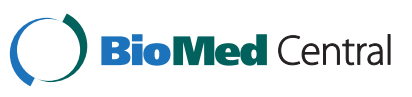


Normal articular cartilage is composed of highly organized proteoglycan and collagen network. Aggrecan along with hyaluronic acid creates huge proteoglycan aggregates, and forms negatively charged glycosaminoglycan (GAG). The structure rigidity of cartilage is conferred mainly by type II collagen. Type II collagen is destroyed in cartilage injury, and it is replaced by type I collagen which possess inferior functions [6]. The degradation of both aggrecan and type II collagen contribute to the progression of OA $[7,8]$.

One of the recent symptomatic treatments employed for OA involves the use of non-steroidal anti-inflammatory drugs (NSAIDs) to block cyclooxygenase (COX) [9]. NSAIDs cause an increase in damage to the cartilage. On the other hand, usage of COX-2 specific class of NSAIDs is known to cause cardiovascular and heart diseases [10]. Thus, there is an urgent need to identify and develop new approaches to treat or inhibit the progression of OA.

Edible Bird's Nest (EBN) was a significant item in the cuisine and pharmacy of the Emperors of China during the $16^{\text {th }}$ century [11]. EBN has been known for its beneficial effect in promoting health in the Chinese for thousands of years [12]. In Traditional Chinese Medicine (TCM), EBN is believed to promote the wellbeing of multiple organs and body systems [13,14]. Previous study showed an avian epidermal growth factor (EGF) extracted from EBN improved the immune function and cell proliferation [15]. Hiroki Nakagawa et al., 2007 [16] found that EBN is rich in proteoglycans containing nonsulfated chondroitin glycosaminoglycan (GAGs) which shares similar properties like the matrix in the cartilage. The proteoglycans isolated contained 83\% carbohydrates, of which 79\% were GalNAc and GlcUA (D-glucuronic acid) in an equimolar ratio. Recently, hot-water extraction of EBN showed the ability to promote cornea cells proliferation and cornea wound healing [17]. To date, all the previous studies demonstrated the beneficial effect of EBN extract prepared by water extraction. Hence, it is hypothesized the water extraction of EBN may prevent human articular chondrocytes (HACs) lose its functions.

Since EBN is produced from swiftlet's saliva, extraction method using organic solvent such as methanol, chloroform and DMSO, which target the non-water soluble active compound, may not be practical. The EBN extract prepared by water extraction mainly contains polysaccharide and glycoprotein, which can easily precipitate through freezing and thawing processes. Thus, we prepared the EBN water extract in a single batch and stored at $4{ }^{\circ} \mathrm{C}$ in order to maintain the uniformity and quality of the extract for the experiment. The present study aimed to measure the effects of EBN extract on the anabolic and catabolic activities of HACs.

\section{Methods}

\section{Edible Bird's nest extract}

Edible Bird's Nest (EBN) extract coded as HMG was obtained from Chemical Engineering Pilot Plant (CEPP), Universiti Teknologi Malaysia (UTM) using an in-house developed method adapted from Oda et al., 1998 [18]. The EBN was collected from a bird's house in Batu Pahat, Johor. Briefly, EBN was grounded in a mortar and pastel; sieved through $0.4 \mathrm{~mm}$ wire mesh to separate feathers and other impurities. The grounded EBN then underwent hot-water extraction at $80^{\circ} \mathrm{C}$. The liquid was then centrifuged to remove non-dissolved constituents. The EBN extract was stored at $4^{\circ} \mathrm{C}$ until used.

\section{Human articular chondrocytes (HACs) isolation and culture}

Prior ethical approval was obtained from the Research and Ethical Committee of Faculty of Medicine, Universiti Kebangsaan Malaysia (UKM project code: 06-01-06SF0257). Cartilage was obtained from six osteoarthritic patients aged between 55-70 years old, who gave their consent during total knee replacement surgery (TKR). All patients had OA knee with lesion scored by International Cartilage Repair Society (ICRS) of grade 4. The cartilage was harvested from the non-weight bearing area of intercondylar notch distal femur. The specimen needed to have a minimum of $300 \mathrm{mg}$ remnant good cartilage, and the isolated HACs expressed collagen type II mRNA with $\pm 20 \%$ differences from the average. Each harvested specimen was placed in normal saline and transported to Biotechnology Laboratory in the Department of Physiology, Faculty of Medicine, UKM within 24 hours. Each specimen was processed individually to isolate the HACs. The cartilage was separated from the bone, washed with phosphate buffered saline (PBS; pH 7.2, Gibco, Grand Island, NY), minced into small pieces and digested with $0.6 \%$ type II collagenase (Worthington Biochemical Corporation, New Jersey) in an orbital incubator at $37^{\circ} \mathrm{C}$ for $6-8$ hours. The cell suspension was then centrifuged at $600 \mathrm{xg}$ for $10 \mathrm{~min}$ to pellet the HACs. The isolated HACs were then cultured in growth medium which consisted of Ham's F-12:Dulbecco's Modified Eagle's Medium (Gibco), 10\% foetal bovine serum (FBS; Gibco), 1\% of antibiotic and antimycotic (Gibco), 1\% of $50 \mu \mathrm{g} / \mathrm{ml}$ ascorbic acid (Sigma, St. Louis, USA) in T25 culture flasks (Nunc, Denmark). All cultures were maintained at $5 \% \mathrm{CO}_{2}$ in a temperature of $37^{\circ} \mathrm{C}$. Upon $80 \%$ confluence, the HACs (Passage 0) were trypsinized using $0.125 \%$ trypsin-EDTA (Gibco) and sub-culture (passage 1) into 6-well plates (Nunc) at the 10,000 cells $/ \mathrm{cm}^{2}$ seeding density. HACs were incubated overnight in growth medium to allow cell attachment before changed to culture medium without FBS and ascorbic acid but supplemented with HMG at various concentrations ranging from $0.00 \%$ (control) to $3.00 \%$, for seven days. 


\section{MTT assay}

The proliferation rate of each cultured HACs in different concentration of HMG was determined by MTT Assay using commercial kit (Sigma, USA) following seven days of culture. The assay was started by adding $2 \mathrm{ml}$ of medium containing $0.5 \mathrm{mg} / \mathrm{ml} \mathrm{MTT}$ into each culture wells and incubated for 4 hours in $5 \% \mathrm{CO}_{2}$ incubator at $37^{\circ} \mathrm{C}$. Consequently, the formed formazan crystal was dissolved by adding $2 \mathrm{ml}$ of MTT Solubilization Solution. The solution was then transferred into $1.5 \mathrm{ml} \mathrm{cu}-$ vette and the absorbance at $570 \mathrm{~nm}$ was taken three times. Two HMG concentrations that gave the highest cell proliferation were then used for the subsequent experiments.

\section{Total RNA extraction}

Total RNA from cultured HACs either in HMG supplemented or control group was extracted using TRI REAGENT (Molecular Research Center, Cincinnati, USA) according to the manufacturer's protocol. Briefly, chloroform was added into the TRI REAGENT homogenate to separate the colourless aqueous contained total RNA. Next, the total RNA was precipitated from the aqueous by mixing with isopropanol and $10 \mu \mathrm{l}$ of Polyacryl carrier (Molecular Research Center). The precipitated RNA was washed with $75 \%$ ethanol and air-dried before being dissolved in water. The yield and the purity of the total RNA was determined by spectrophotometer (Bio-Rad, Hercules, USA).

\section{CDNA synthesis}

SuperScript $^{\mathrm{TM}}$ III First-Strand Synthesis SuperMix (Invitrogen, Carlsbad, USA) was used to synthesis cDNA from extracted total RNA according to the manufacturer's protocol. The reverse transcription was carried out at $50.0^{\circ} \mathrm{C}$ for 30 minutes and the cDNA was stored at $-20^{\circ} \mathrm{C}$ until use.

\section{Quantitative polymerase chain reaction (Q PCR)}

Primers used for quantitative PCR were designed based on the sequences published in GenBank using Primer-3 software. The primers sequenced were listed (Table 1). Quantitative PCR was performed at $94^{\circ} \mathrm{C}$ (pre-denaturation step), $2 \mathrm{~min}$; 40 cycles of denaturation at $94^{\circ} \mathrm{C}, 10 \mathrm{sec}$; amplification at $61^{\circ} \mathrm{C}, 30 \mathrm{sec}$ and followed by melting curve analysis to verify the specificity of the PCR products. The specificity of PCR product was also examined by agarose gel electrophoresis. Glycerylaldehyde-3-phosphate dehydrogenase (GAPDH) was used as the reference gene for the data normalization.

\section{Prostaglandin E2 $\left(\mathrm{PGE}_{2}\right)$ quantification}

The culture medium from the cultured HACs at day seven was collected and kept frozen until the concentration of
Table 1 Primers sequence of genes for quantitative PCR

\begin{tabular}{|c|c|c|c|}
\hline $\begin{array}{l}\text { Gene } \\
\text { Name }\end{array}$ & $\begin{array}{c}\text { GenBank } \\
\text { Accession } \\
\text { Number }\end{array}$ & Primer Sequence 5'-3' & $\begin{array}{l}\text { PCR product } \\
\text { size (bp) }\end{array}$ \\
\hline \multirow[t]{2}{*}{ GAPDH } & NM_002046 & $\begin{array}{l}\text { F: } 5^{\prime}-\text { tcc ctg agc tga acg } \\
\text { gga ag-3' }\end{array}$ & 217 \\
\hline & & $\begin{array}{l}\text { R: } 5^{\prime}-\text { gga gga gtg ggt } \\
\text { gtc gct gt-3' }\end{array}$ & \\
\hline \multirow[t]{2}{*}{ COL I } & NM_000088 & $\begin{array}{l}\text { F: 5'-agg gct cca acg } \\
\text { aga tcg aga-3' }\end{array}$ & 222 \\
\hline & & $\begin{array}{l}\text { R: 5'-tac agg aag cag } \\
\text { aca ggg cca-3' }\end{array}$ & \\
\hline \multirow[t]{2}{*}{ COL ॥ } & NM_001844 & $\begin{array}{l}\text { F: 5'-cta tct gga cga agc } \\
\text { agc tgg ca-3' }\end{array}$ & 209 \\
\hline & & $\begin{array}{l}\text { R: } 5^{\prime} \text {-atg ggt gca atg tca } \\
\text { atg atgg-3' }\end{array}$ & \\
\hline \multirow[t]{2}{*}{$\mathrm{ACP}$} & NM_001135 & $\begin{array}{l}\text { F: 5'-gcg gag gaa gtc } \\
\text { ggt gaa ga-3' }\end{array}$ & 183 \\
\hline & & $\begin{array}{l}\text { R: } 5^{\prime}-\mathrm{ccc} \text { tct cgc ttc agg } \\
\text { tca gc- } 3^{\prime}\end{array}$ & \\
\hline \multirow[t]{2}{*}{ SOX-9 } & NM_000346 & $\begin{array}{l}\text { F: } 5^{\prime}-\mathrm{cac} \text { tgt tac cgc cac } \\
\text { ttc } c \mathrm{c}-3^{\prime}\end{array}$ & 236 \\
\hline & & $\begin{array}{l}\text { R: 5'-acc agc gga agt } \\
\text { ccc ctt cg-3' }\end{array}$ & \\
\hline \multirow[t]{2}{*}{$\mathrm{IL}-1$} & NM_000576 & $\begin{array}{l}\text { F: 5'-gga caa gct gag } \\
\text { gaa gat gc-3' }\end{array}$ & 120 \\
\hline & & $\begin{array}{l}\text { R: } 5^{\prime} \text {-tcg tta tcc cat gtg } \\
\text { tcg aa-3' }\end{array}$ & \\
\hline \multirow[t]{2}{*}{$\mathrm{IL}-6$} & NM_000600 & $\begin{array}{l}\text { F: 5'-tac ccc cag gag } \\
\text { aag att cc-3' }\end{array}$ & 175 \\
\hline & & $\begin{array}{l}\text { R: } 5^{\prime} \text {-ttt tct gaa agt gcc } \\
\text { tct tt-3' }\end{array}$ & \\
\hline \multirow[t]{2}{*}{ IL-8 } & NM_000584 & $\begin{array}{l}\text { F: 5'-gtg cag ttt tgc caa } \\
\text { gga gt-3' }\end{array}$ & 196 \\
\hline & & $\begin{array}{l}\text { R: } 5^{\prime}-\mathrm{ctc} \text { tgc acc cag ttt } \\
\text { tcc tt-3' }\end{array}$ & \\
\hline \multirow[t]{2}{*}{ MMP1 } & NM_002421 & $\begin{array}{l}\text { F: 5'-agg gtt gaa aag } \\
\text { cat gag ca-3' }\end{array}$ & 111 \\
\hline & & $\begin{array}{l}\text { R: 5'-ctg gtt gaa aag cat } \\
\text { gag ca-3' }\end{array}$ & \\
\hline \multirow[t]{2}{*}{ MMP3 } & NM_002422 & $\begin{array}{l}F: 5^{\prime}-\operatorname{tgc} \text { ttt gtc ctt tga } \\
\operatorname{tgc} \operatorname{tg}-3^{\prime}\end{array}$ & 135 \\
\hline & & $\begin{array}{l}\text { R: 5'-gga aga gat ggc } \\
\text { caa aat ga-3' }\end{array}$ & \\
\hline \multirow[t]{2}{*}{ MMP13 } & NM_002427 & $\begin{array}{l}\text { F: 5'-ggt ctt gac cac tcc } \\
\text { aag gac-3' }\end{array}$ & 221 \\
\hline & & $\begin{array}{l}\text { R: 5'-ctc ctc gga gac } \\
\text { tgg taa tgg-3' }\end{array}$ & \\
\hline \multirow[t]{2}{*}{ iNOS } & NM_000625 & $\begin{array}{l}\text { F: } 5^{\prime} \text {-aca agc cta ccc ctc } \\
\text { cag at- } 3^{\prime}\end{array}$ & 158 \\
\hline & & $\begin{array}{l}\text { R: } 5^{\prime} \text {-tcc cgt cag ttg gta } \\
\text { ggt tc-3' }\end{array}$ & \\
\hline \multirow[t]{2}{*}{$\operatorname{cox}-2$} & NM_000963 & $\begin{array}{l}\text { F: } 5^{\prime} \text {-tga gca tct acg gtt } \\
\text { tgc tg-3' }\end{array}$ & 158 \\
\hline & & $\begin{array}{l}R: 5^{\prime} \text {-tgc ttg tct gga aca } \\
\text { act gc-3' }\end{array}$ & \\
\hline
\end{tabular}


Prostaglandins $\mathrm{E}_{2}\left(\mathrm{PGE}_{2}\right)$ was measured with Parameter ${ }^{\mathrm{Tm}}$ $\mathrm{PGE}_{2}$ Immunoassay Kit (R\&D Systems Inc, USA). The sample preparation and reaction protocol was following the manufacturer's instruction. The absorbance at $450 \mathrm{~nm}$ was acquired three times. A standard curve was plotted, and the amount of PGE2 released in each sample was determined from the standard curve.

\section{Sulphated glycosaminoglycan (sGAG) quantification}

The amount of sGAG in each group was measured by 1,9-dimethylmethylene blue (DMMB) assay. Chondroitin Sulfate S (Sigma) was used as the control to plot the standard curve. The sGAG concentration in the sample was normalised against the DNA content in the respective specimens.

\section{Results}

\section{HACs proliferation with HMG supplementation}

The results showed HMG supplementation at low concentration $(0.05 \%-1.00 \%)$ promoted the proliferation of HACs (Figure 1). However, HACs proliferation was slower than the control group when HMG concentration was higher than $1.00 \%$. HACs recorded significant lower proliferation in cultures supplemented with HMG at $1.80 \%$ and $3.00 \%$ concentration. Subsequently, HMG at concentration of $0.50 \%$ and $1.00 \%$ were chosen for the following tests.

\section{Morphological features of HACs in the culture}

The morphological feature of HACs cultured in various HMG concentrations was captured under an inverted microscope (Figure 2). HACs cultured at P0 in the medium supplemented with $10 \%$ FBS appeared in polygonal shape (Figure 2A). When HACs were cultured in the medium without FBS, it lost its polygonal shape and changed to dendrite-like features (Figure 2B). HACs cultured in medium supplemented with HMG recovered partially of the polygonal feature with some cells appearing as fibroblastic (Figure 2C).

\section{HMG effects on the mRNA expression of HACs}

HMG supplementation was able to reduce HACs expression on MMP1 and MMP3 mRNA in a dose-dependent manner (Figure 3a and $3 \mathrm{~b}$ ). HMG concentration at $1.00 \%$ significantly reduced the MMP1 expression by -13.27 fold compared to the control group $(\mathrm{P}=0.010)$ and -5.67 fold compared to the $0.5 \%$ HMG group $(\mathrm{P}=0.016)$. HMG concentration at $1.00 \%$ significantly decreased MMP3 expression by -1.56 fold $(\mathrm{P}=0.047)$ compared to the control group. However, HMG caused no significant increment in the MMP13 expression in HACs compared to the control group (Figure 3c).

HMG also caused down-regulation of IL-1, IL-6 and IL-8 mRNA expression in HACs (Figure 4). However, only the pro-inflammatory marker, IL-1 expression was significantly decreased by $1.00 \%$ HMG supplementation $(-2.38$ fold, $\mathrm{P}=0.025$; Figure $4 \mathrm{a})$. Both the catabolic mediators; COX-2 and iNOS mRNA expression in HACs reduced with the HMG supplementation (Figure 5). HMG at $1.00 \%$ concentration reduced the COX-2 expression by -2.64 fold and iNOS expression by -1.4 fold in cultured HACs. However, the reduction was not significant compared to the control group.

HMG supplementation increased the anabolic gene expression of cultured HACs. The expression of COL I, COL II, ACP and SOX-9 mRNA was increased in a dosedependent manner of HMG supplementation (Figure 6). COL I expression was increased 1.15fold; COL II at +1.28 fold; ACP at +1.49 fold and SOX -9 at +2.13 fold with $1.00 \%$ HMG supplementation. The chondrocytes phenotype index (ratio of COL II/COL I) also increased in a dose-dependent manner with HMG supplementation. The ratio of COL II/ COL I gradually increased from

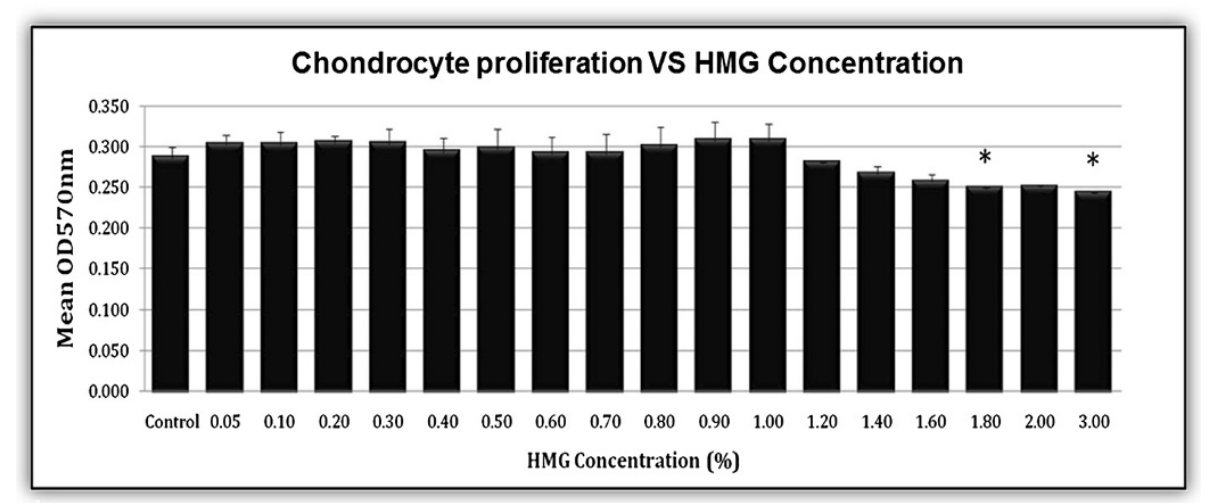

Figure 1 Human articular chondrocytes cultured in various concentration of HMG in the culture medium. The values were expressed as mean $\pm \mathrm{SEM}, \mathrm{n}=6$. * Significant lower proliferation compared to the control group $(\mathrm{P}<0.05 \%)$. 

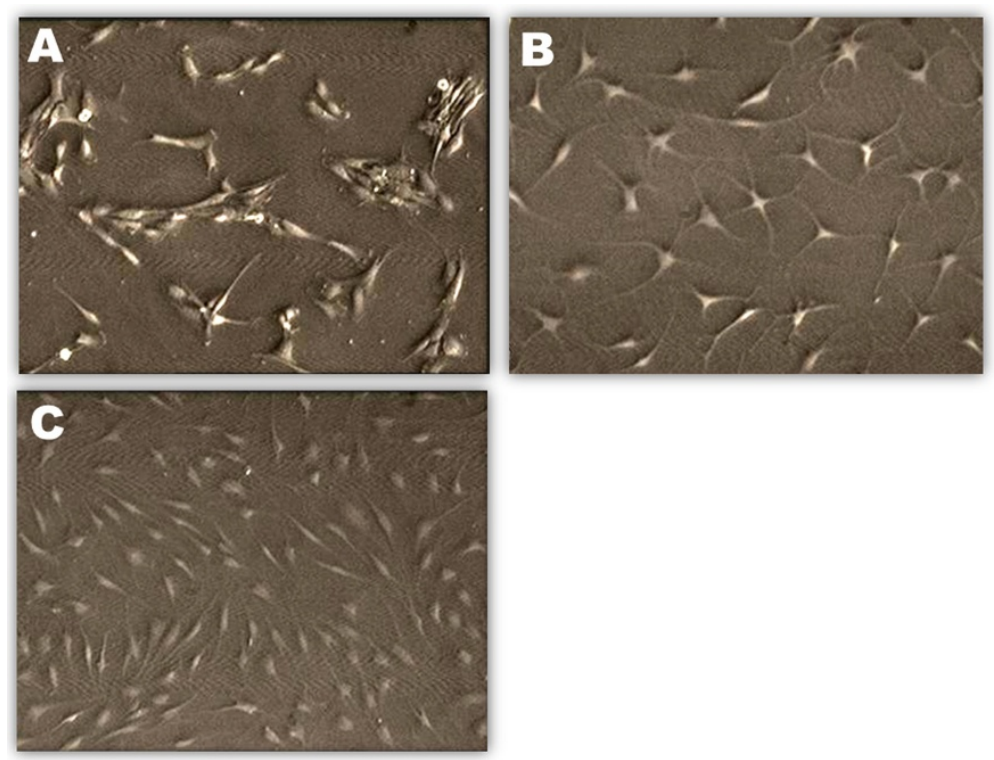

Figure 2 Morphological features of cultured human articular chondrocytes (HACs). A) Freshly isolated HACs cultured in medium nourished with $10 \%$ FBS, B) HACs cultured in medium without FBS (control), C) HACs cultured in medium supplemented with $1.00 \%$ HMG. Magnification $100 \times$.

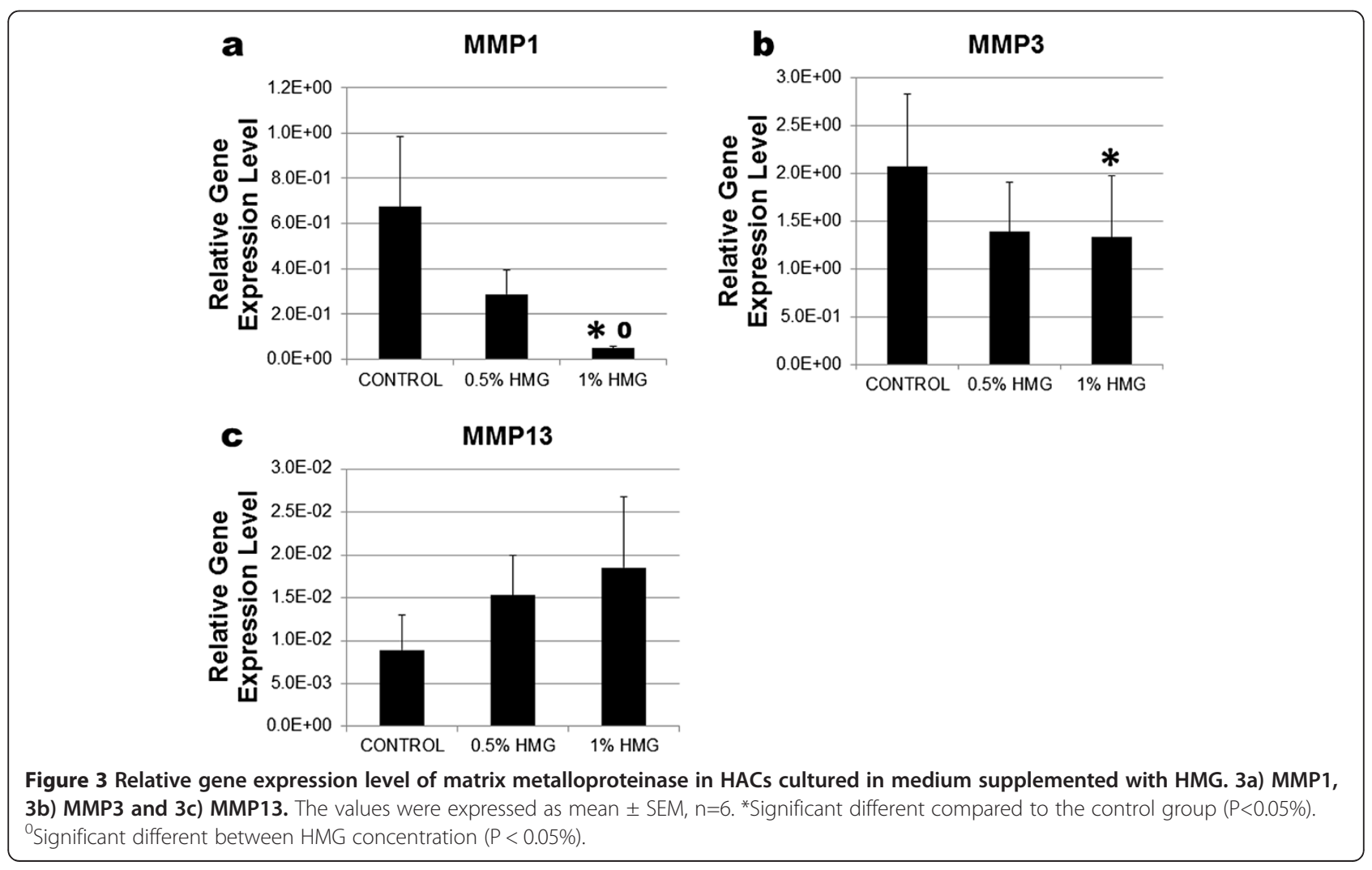



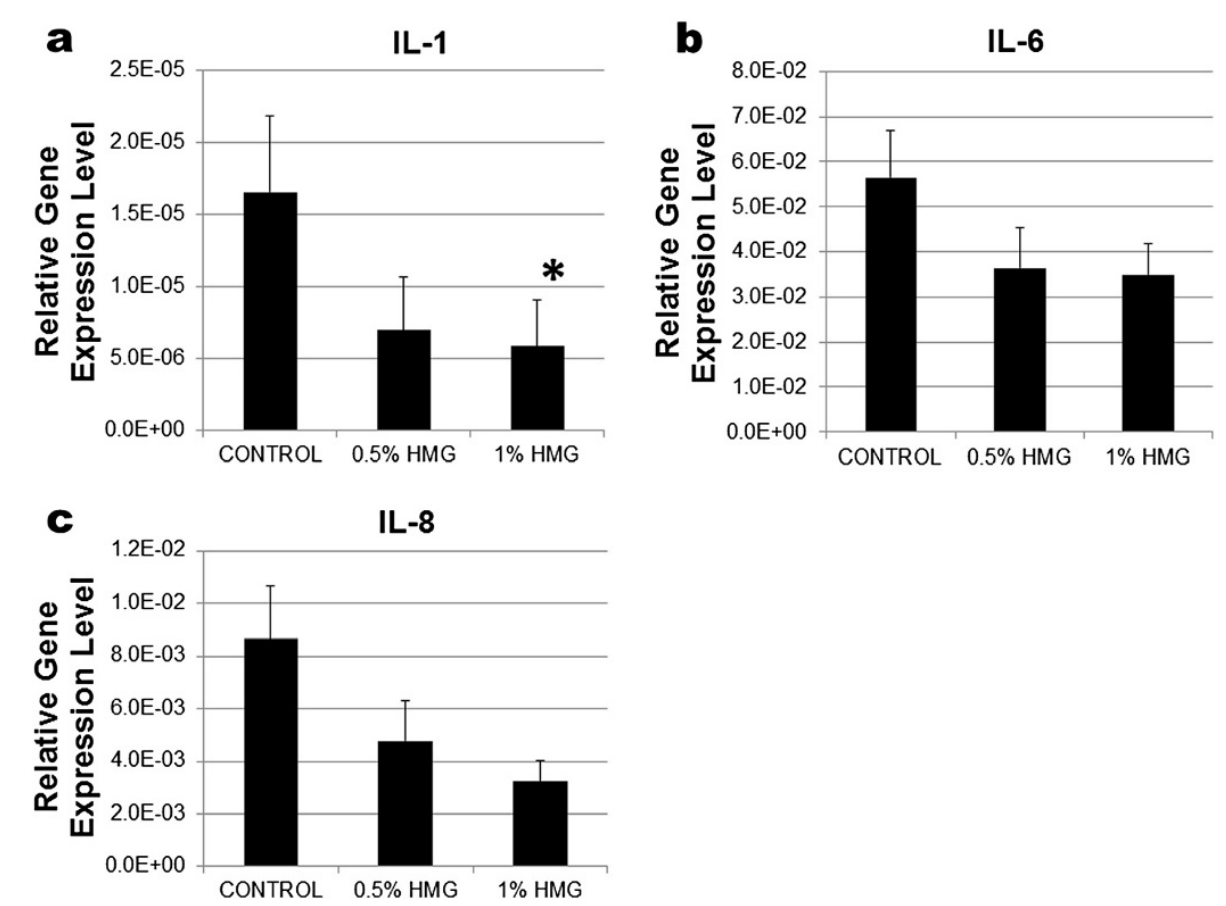

Figure 4 Relative gene expression level of pro-inflammatory markers in HACs cultured in medium supplemented with HMG. 4a) IL-1, 4b) IL-6 and 4c) IL-8. The values were expressed as mean \pm SEM, $n=6$. ${ }^{*}$ Significant different compare to the control group $(P<0.05 \%)$.

1.19fold in 0.5\% HMG to 1.33 fold in $1.00 \%$ HMG supplementation (Table 2).

\section{Prostaglandin $\mathrm{E}_{2}$ production in HACs}

The amount of $\mathrm{PGE}_{2}$ produced in HACs was decreased by -1.12 fold in $0.50 \%$ HMG supplementation. The higher concentration of HMG at $1.00 \%$ caused a significant decrease in $\mathrm{PGE}_{2}$ production by -1.92 fold compared to the control group ( $\mathrm{P}=0.025$; Figure 7$)$.

Sulphated glycosaminoglycan (sGAG) production in HACs The amount of sGAG produced by the HACs in the control group was 2539.83 \pm 705.67 sGAG/DNA. Supple- mentation of HMG into the culture medium caused an increase in the production of sGAG to $4718.46 \pm 1421.08$ sGAG/DNA (0.50\% HMG) and 3572.58 \pm 1357.89 sGAG/ DNA in $1.00 \%$ HMG (Figure 8).

\section{Discussion}

The results of the present study showed EBN extract coded HMG worked effectively in low concentration on the HAC cultures. HMG was able to reduce the dendritic changes on HACs due to culture in serum-free medium. A previous study showed cultured chondrocytes changes its morphology when dedifferentiated in monolayer culture [19]. Only cultures with round-polygonal chondrocytes could
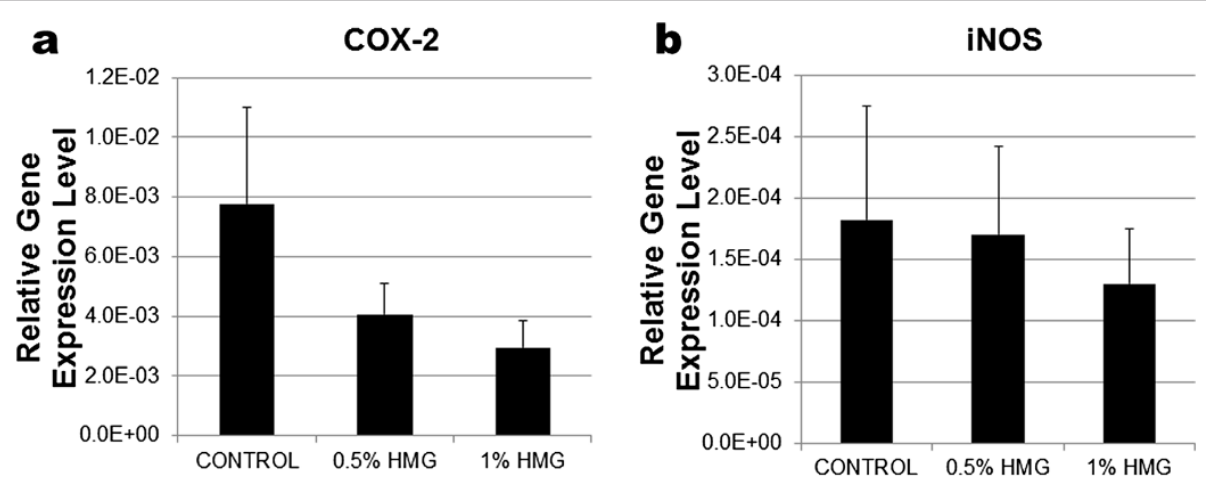

Figure 5 Relative gene expression level of $5 \mathrm{a}$ ) COX-2 and 5b) iNOS in HACs cultured in medium supplemented with HMG. The values were expressed as mean $\pm \mathrm{SEM}, \mathrm{n}=6$. 

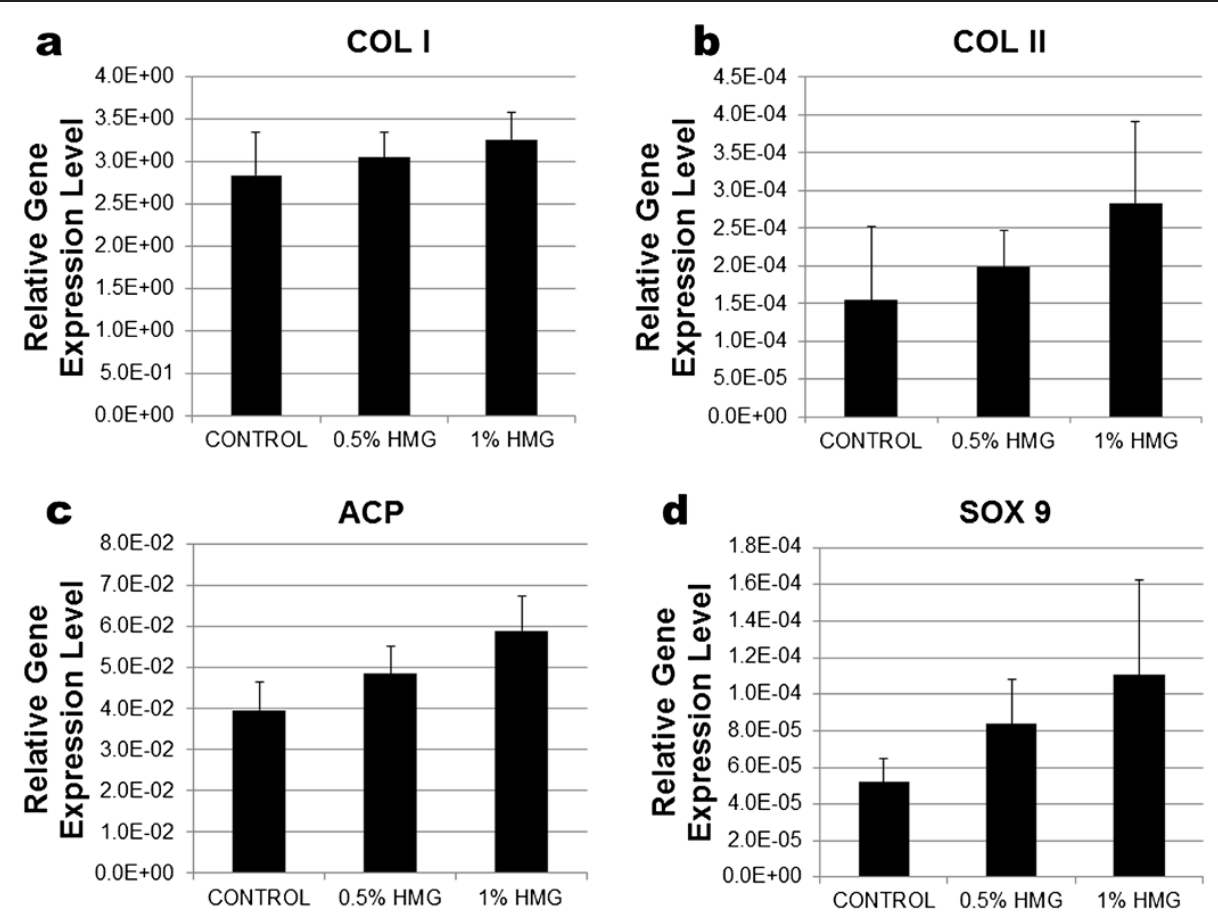

Figure 6 Relative gene expression level of anabolic mediator in HACs cultured in medium supplemented with HMG. 6a) Type I collagen (COL 1), 6b) Type II collagen (COL II), 6c) ACP and 6d) SOX-9. The values were expressed as mean \pm SEM, $n=6$.

synthesize type II collagen and maintain the differentiated phenotype [20]. Thus, HMG was able to reduce the dendritic changes and dedifferentiation on cultured HACs compared to the control group.

Matrix metalloproteinases (MMPs) are zinc-endopeptidases involved in numerous physiological and pathological events involving cartilage including degradation of both the endogenous and newly synthesized extracellular matrix proteins [21,22]. HMG supplementation may significantly decrease the expression of MMP1 and MMP3 in HACs compared to the control group. This helps in reducing the continuous destruction of cartilage and the degenerative progression of osteoarthritic cartilage [18,23]. The expression of pro-inflammatory cytokines (IL-1, IL-6 and IL-8) in cultured HACs supplemented with HMG was lower compared to the control group. A significant decrease in IL-1 was observed in the HMG supplemented group. IL-1 interacts with various cytokines including IL-6 and IL-8 [24] to induce the secretion of MMPs and reactive oxygen species that destroy the cartilage matrix [25]. The capability of

Table 2 Ratio of COL II/COL I in HACs cultured in medium supplemented with HMG

\begin{tabular}{cc}
\hline HMG Concentration & COL II/COL I Index Relative to Control \\
\hline Control & 1 \\
$0.5 \% \mathrm{HMG}$ & 1.195 \\
$1.0 \% \mathrm{HMG}$ & 1.33 \\
\hline
\end{tabular}

HMG to suppress these cytokine's expression may further decrease the MMPs activity and help in the reduction of the cartilage destruction [22].

In response to IL-1, chondrocytes increase the synthesis of nitric oxide $(\mathrm{NO})$ and prostaglandin $\mathrm{E}_{2}\left(\mathrm{PGE}_{2}\right)$ through the activation of iNOS and cyclooxygenase-2 (COX-2) [26-28]. In this study, COX-2 and iNOS expression was reduced in HACs supplemented with HMG. Furthermore, $\mathrm{PGE}_{2}$ production was significantly decreased in HMG supplemented HAC cultures compared to the control group. The similar results were demonstrated in a previous study which used avocado

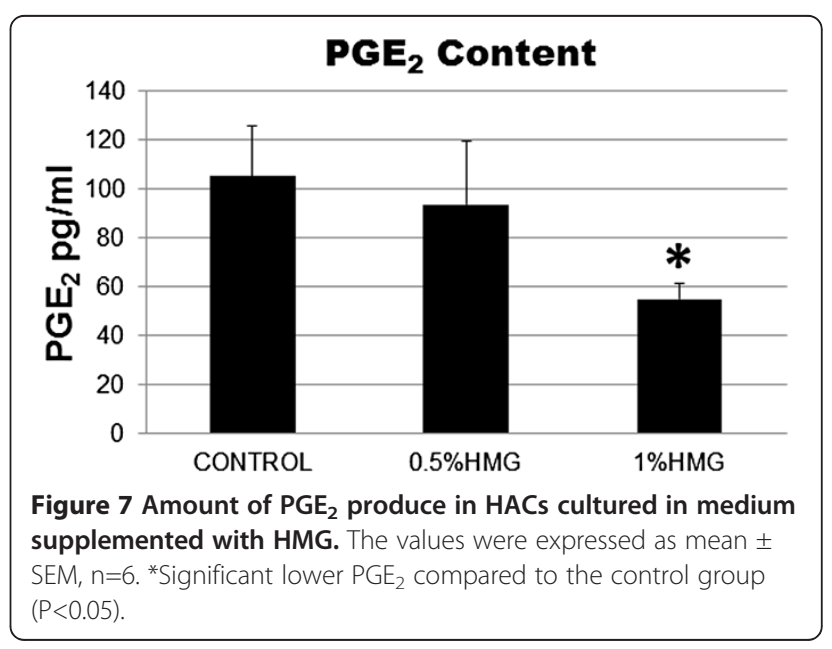




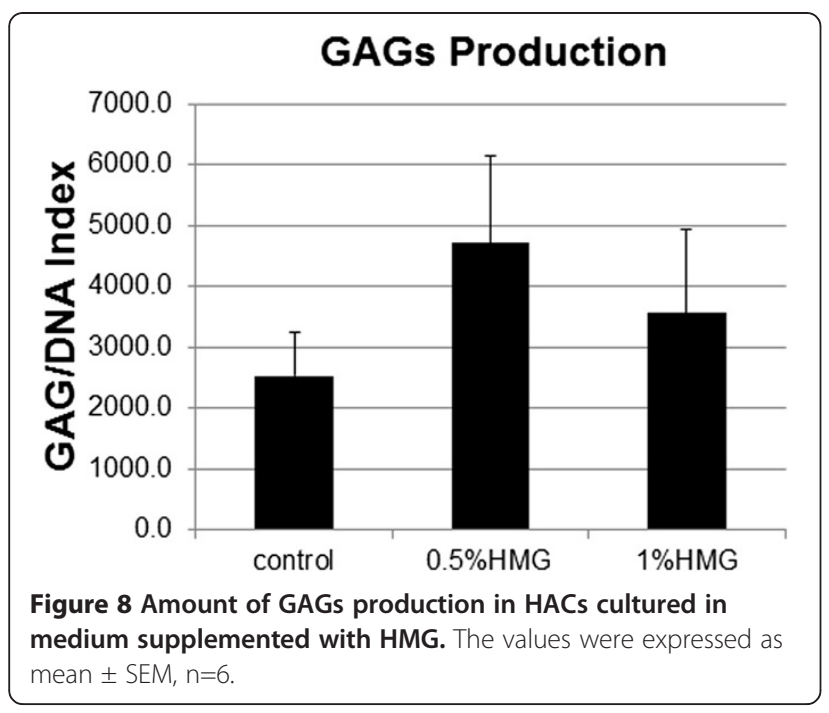

soybeans extract [29]. Thus, the ability of HMG to decrease $\mathrm{PGE}_{2}$ production and down-regulate iNOS and COX-2 expression indicated its potential use in slowing down the cartilage destruction in OA.

In chondrocyte monolayer culture, dedifferentiation started when type II collagen expression reduced together with an increase of type I collagen (COL I) expression [30]. In this study, the expression of COL I and COL II mRNA did not state significant differences between the HMG supplemented groups compared to the control group. However, the ratio of COL II/COL I was increased with the supplementation of HMG. The increase of COL II/COL I ratio is necessary to reduce the chondrocytes' dedifferentiation and improve the chondrocytes' phenotype [31]. Besides, HMG supplementation also caused a gradual increase in SOX-9 and aggrecan core protein (ACP) expression in cultured HACs compared to the control group. SOX-9 is a transcription factor in chondrogenesis, and its expression is essential for the anabolic activity of the chondrocyte as well as the differentiation of stem cells [32]. While ACP is a major component of the cartilage matrix which helps the cartilage in sustaining continuous mechanical loads [33]. In the present study, both the ACP mRNA expression and sulphated glycosaminoglycans (GAGs) production were increased by HMG supplementation although no significant difference was recorded. Overall, HMG supplementation may need a longer duration of action before it can cause a significant increase in the anabolic activity of the cultured HACs.

\section{Conclusion}

The catabolic activity of cultured chondrocyte was significantly reduced with the HMG supplementation. The ability of HMG to down-regulate MMPs, cytokines and other catabolic mediator expression suggest that HMG may be a potential anti-inflammatory/anti-degenerative agent in treating osteoarthritis. HMG also causes an increase in the chondrocytes' anabolic activity, although longer duration may be needed to demonstrate the significant changes. Thus, it is concluded that HMG is a potential chondro-protective agent.

\section{Competing interests}

The authors declare that they have no competing interest.

\section{Authors' contributions}

$\mathrm{KHC}$ had involved in the design of the study, coordination the experiment and written the manuscript. KN had carried out the study, performed the statistical analysis and drafted the manuscript. NHMY had provided the samples for the study and helped to draft the manuscript. LCT had participated in the sequence alignment, revised the manuscript. ETाT had participated in the design of the study, helped to draft the manuscript. LTH conceived the study and participated in the design and coordination. RAA helped to draft and revise the manuscript. All authors read and approved the final manuscript.

\section{Acknowledgement}

This study was supported by ScienceFund grant 06-01-06-SF0257 from the Ministry of Science, Technology and Innovation of Malaysia. The authors acknowledge the technical English editing by Professor Srijit Das.

\section{Author details}

${ }^{1}$ Department of Physiology, Faculty of Medicine, Universiti Kebangsaan Malaysia, Jalan Raja Muda Abdul Aziz, Kuala Lumpur 50300, Malaysia. ${ }^{2}$ Institute of Bioproduct Development, Universiti Teknologi Malaysia, Skudai, Johor 81310, Malaysia. ${ }^{3}$ Department of Orthopaedic and Traumatology, Faculty of Medicine, Universiti Kebangsaan Malaysia, Jalan Yaacob Latif Bandar Tun Razak, Kuala Lumpur, Cheras 56000, Malaysia. ${ }^{4}$ Faculty of Chemical Engineering, Universiti Teknologi Malaysia, Skudai, Johor 81310, Malaysia. ${ }^{5}$ Food Technology Department, Faculty of Applied Sciences, Universiti Teknologi MARA, Selangor, Shah Alam 40450, Malaysia.

Received: 12 July 2012 Accepted: 11 January 2013

Published: 22 January 2013

\section{References}

1. Cardile V, Panico A, Gentile B, Borrelli F, Russo A: Effects of propolis on human cartilage and chondrocytes. Life Science 2003, 73:1027-1035.

2. Naoki I, Toshihisa K, Robin P: Mechanism of cartilage destruction in osteoarthritis. Nogoya Journal of Medical Science 2002, 65:73-84.

3. $Y u$ CL, Sun KH, Shei SC, Tsai CY, Tsai ST, Wang JC, Liao TS, Lin WM, Chen HL, Yu HS, Han SH: Interleukin-8 modulates interleukin -1i beta, interleukin-6 and tumor necrosis factor alpha release form normal human mononuclear cells. Immunopharmacology 1994, 27:207-214.

4. Nietfeld JJ, Wilbrink B, Helle M, Van RJL, Den OW, Swaak AJ, Huber B: Interleukin-1-induced interleukin-6 is required for the inhibition of proteoglycan synthesis by interleukin-1 in human articular cartilage. Arthritis Rheum 1990, 33:1695-1701.

5. Taskiran D, Stefanovic-Racic M, Geogescu H, Evans C: Nitric oxide mediates suppression of cartilage proteoglycan synthesis by interleukin-1. Biochemistry and Biophysical Research Communication 1994, 200:142-148.

6. Poole AR: An introduction to the pathophysiology of osteoarthritis. Frontier in Bosciences 1999, 4(1):D662-D670.

7. Nagase $\mathrm{H}$, Kashiwagi M: Aggrecanases and cartilage matrix degradation. Arthritis Res Ther 2003, 5(2):94-103.

8. Yagi R, McBurney D, Laverty D: Intra joint comparisons of gene expression patterns in human osteoarthritis suggest a change in chondrocytes phenotype. J Orthop Res 2005, 23:1128-1138.

9. Kran PM, Van der Berg WM: Anabolic and destructive mediator in osteoarthritic. Current Opinion in Nutrition and Metabolic Care 2000, 3:205-211.

10. Graham DJ, Campen D, Hui R, Spence M, Cheetham C, Levy G, Shoor S, Ray WA: Risk of acute myocardial infarction and sudden cardiac death in patients treated by cyclo-oxygenase 2 selective and non-selective non-steroidal antiinflammatory drugs: Nested Case-control study. Lancet 2005, 365:475-481. 
11. Lau ASM, Melville DS: International trade in Swiftlet nests with special reference to Hong Kong. Cambridge (UK): Traffic International; 1994.

12. Ou K, Seow TK, Liang RCMY, Lee BW, Goh DLM, Chua KY, Chung MCC: Identification of serine protease homologue in bird's nest by an integrated proteomics approach. Electrophoresis 2001, 22(16):3589-3595.

13. Hobbs JJ: Problems in harvest of edible bird's nest in Sarawak and Sabah, Malaysian Borneo. Biodivers Conserv 2004, 13:2209-2226.

14. Chan SW: Review of scientific research on edible bird's nest, Department of Applied Biology and Chemical Technology. The Hong Kong Polytechnic University; 2006. http://www.hkfsta.com.hk/articles/special/article7.htm.

15. Kong YC, Keung WM, Yip T, Ko KM, Tsao SW, Ng MH: Evidence that epidermal growth factor is present in swiftlets (Collocalia) nest. Comparative Biochemistry and Physiology Part B. Biochemistry and Molecular Biology 1987, 87(2):221-226.

16. Hiroki N, Yoichiro H, Toshihisa S, Su CL, Karol M, Kittiwan K, Shuji M, Kazuyuki S, Yu TL: Occurrence of a nonsulfated chondroitin proteoglycan in the dried saliva of Collocalia swiftlets (edible bird's-nest). Glycobiology 2007, 17(2):157-164.

17. Zainal AF, Chua KH, Ng SL, Mohd RES, Lee TH, Norzana AG: Effects of edible bird's nest (EBN) on cultured rabbit corneal keratocytes. BMC Complement Altern Med 2011, 11(1):94.

18. Tsutsumi R, Ito H, Hiramitsu T, Nishitani K, Akiyoshi T, Yasuda T, Nakamura T: Celecoxib inhibits production of MMP and NO via downregulation of NF-KB and JNK in a PGE2 independent manner in human articular chondrocytes. Rheumatol Int 2008, 28:727-736.

19. Loty S, Sautier JM, Forest N: Phenotypic modulation of nasal septal chondrocytes by cytoskeleton modification. Biorheology 2000, 37(1-2):117-125

20. Mar KVD, Gauss V, Mark HVD, Muller PB: Relationship between cell shape and type of collagen synthesised as chondrocytes lose their cartilage phenotype in culture. Nature 1977, 267:531-532.

21. LeMaitre V, D'Armiento J: Matrix Metalloproteinases in Development and Disease. Birth Defects Research 2006, 78(Part C):1-10.

22. Goldring MB, Otero M, Plumb DA, Dragomir C, Favero M, Hachem KE, Hashimoto K, Roach HI, Olivoto E, Borzi RM, Marcu KB: Roles of inflammatory and anabolic cytokines in cartilage metabolism: signals and multiple effectors converge upon MMP-13 regulation in osteoarthritis. European Cell and Materials 2011, 21:202-220.

23. Tetlow LC, Adlam DJ, Woolley DE: Matrix Metalloproteinase and proinflammatory cytokine production by chondrocytes of human osteoarthritic cartilage: Associations with degenerative changes. Arthritis Rheum 2001, 44(3):585-594

24. Bandara G, Georgescu HI, Lin CW, Evans CH: Synovial activation of chondrocytes: evidence for complex cytokine interactions. Agents Actions 1991, 34:285-288.

25. Martel-Pelletier J, Zafarullah M, Kodama S, Pelletier JP: In vitro effects of interleukin 1 on the synthesis of metalloproteases, TIMP, plasminogen activators and inhibitors in human articular cartilage. J Rheumatol 1991, 18(27):80-84.

26. Goldring SR, Goldring MB: The role of cytokines in cartilage matrix degeneration in osteoarthritis. Clinical Orthopeadic 2004, 427(suppl):S27-S36.

27. Steenport M, Faisal Khan KM, Baoheng D, Barnhard SE, Dannenberg AJ, Falcone DJ: Matrix metalloproteinase (MMP)-1 and MMP-3 induced Macrophage MMP-9: Evidence for the role of TNF-a and cyclooxygenase2. J Immunol 2009, 183:8119-8127.

28. Nieminen R, Korhonen R, Moilanen T, Clark AR, Moilanen E: Aurothiomalate inhibits cyclooxygenase 2, matrix metalloproteinase 3 and interleukin-6 expression in chondrocytes by increasing MAPK phosphatase 1 expression and decreasing p38 phosphorylation: MAPK phosphatase 1 as a novel target for anti-rheumatic drugs. Arthritis Rheum 2010, 62(6):1650-1659

29. Au RY, Al-Talib TK, Au AY, Phan PV, Frondoza CG: Avocado soybean unsaponifiables (ASU) suppress TNF- $a$, IL-1 $\beta$ COX-2, iNOS gene expression and prostaglandin E2 and oxide production in articular chondrocytes and monocytes/macrophages. Osteoarthr Cartil 2007, 15:1249-1255.

30. Chua KH, Aminuddin BS, Fuzina NH, Ruszymah BHI: Basic fibroblast growth factor with human serum supplementation: enhancement of human chondrocytes proliferation and promotion of cartilage regeneration. Singapore Med J 2007, 48(4):324-332.
31. Chua KH, Aminuddin BS, Fuzina NH, Ruszymah BHI: Insulin-TransferrinSelenium prevents human chondrocytes dedifferentation and promote the formation of high quality tissue engineering human hyaline cartilage. Eur Cell Mater 2005, 9:58-67.

32. Hamid AA, Idrus RB, Saim AB, Sathappan S, Chua KH: Characterization of human adipose-derived stem cells and expression of chondrogenic genes during induction of cartilage differentiation. Clinics (Sao Paulo) 2012, 67(2):99-106.

33. lozzo RV: Matrix proteoglycans: from molecular design to cellular function. Annual review Biochamistry 1998, 67:609-652.

doi:10.1186/1472-6882-13-19

Cite this article as: Chua et al:: Edible Bird's nest extract as a chondroprotective agent for human chondrocytes isolated from osteoarthritic knee: in vitro study. BMC Complementary and Alternative Medicine 2013 13:19.

\section{Submit your next manuscript to BioMed Central and take full advantage of:}

- Convenient online submission

- Thorough peer review

- No space constraints or color figure charges

- Immediate publication on acceptance

- Inclusion in PubMed, CAS, Scopus and Google Scholar

- Research which is freely available for redistribution 